\title{
Criação de aplicativo gamificado para o engajamento nas aulas de Educação Física
}

\author{
Fernanda da Silva, Maria Augusta D’Arienzo, Diego Parizotto, Adriano \\ Teixeira \\ Universidade de Passo Fundo (UPF) - Passo Fundo, RS - Brasil \\ 59725@upf.br, 52032@upf.br, 141965@upf.br, teixeira@upf.br
}

\begin{abstract}
The article presents the conception of a computerized application to assist physical education teachers in the process of fostering students engagement with the practice of physical activity. At first, an analysis of Gamification techniques was made, how they can be used in an application and how they affect users' motivation. In a second moment, an application was developed making use of the gamification techniques studied previously. This process allows to suggest that it is possible to engage students in the practice of physical activity through this App.
\end{abstract}

Resumo. $O$ artigo apresenta a concepção de um aplicativo gamificado para auxiliar o professores de educação física no processo de fomento do engajamento dos alunos com a prática da atividade física. Em um primeiro momento foi feita uma análise das técnicas de Gamificação, de que maneira podem ser utilizadas em um aplicativo e de que forma elas afetam a motivação dos usuários. Em um segundo momento, foi desenvolvido um aplicativo fazendo uso das técnicas de gamificação estudadas anteriormente. Tal processo permite sugerir que é possível engajar estudantes para a prática da atividade fisica por meio deste App gamificado.

\section{Introdução}

O contexto tecnológico atual é caracterizado pelo acesso generalizado a grandes quantidades de informações, o qual assume papel importante na formação social e cultural do indivíduo. Os chamados ambientes virtuais de aprendizagem (AVA) estão se difundindo nas diversas áreas do conhecimento. Conforme relata Almeida (2008) a inclusão das Tecnologias da Informação e Comunicação (TICs) na educação acaba por restringir-se à incorporação nas escolas dos dispositivos tecnológicos caracterizados pela conexão à internet e mobilidade.

Há algum tempo os games estão sendo usados como oportunidades de aprendizagem para trabalhar competências cognitivas, memória, atenção visual e resolução de problemas em escolares (De Lisie e Wolford, 2002). Os jogos educativos baseiam-se no interesse pelo lúdico e podem promover ambientes de aprendizagem atraentes (Falkembach, 2006). Jogar faz parte da essência humana e os jogos se tornam uma forma de entretenimento cada vez mais presente entre públicos de todas as idades. Recentemente surgiu uma tendência chamada gamificação que pode ser compreendida, em linhas gerais, como a utilização dos elementos de jogos e game design fora do 
VIII Congresso Brasileiro de Informática na Educação (CBIE 2019)

Anais do XXV Workshop de Informática na Escola (WIE 2019)

contexto de jogos. Segundo Vianna et al. (2013), o uso de mecânicas de jogos em ambientes diversos, com o objetivo de incrementar a participação, gerar engajamento e comprometimento por parte dos usuários também é um fenômeno que vem da popularidade dos games e da sua capacidade particular de motivar a ação, resolver problemas e aumentar o potencial de aprendizagem nas mais diversas áreas de conhecimento. Kapp (apud Borges et al. 2013), define gamificação como a aplicação de elementos utilizados no desenvolvimento de jogos eletrônicos, tais como: componentes (estética), mecânicas e dinâmicas, porém em outros contextos não relacionados a jogos.

O desenvolvimento cognitivo está relacionado à implementação de novas estratégias no processo educativo. Os elementos de gamificação estão se tornando um assunto recorrente em processos de engajamento e colaboração que buscam adesão de indivíduos, que possuem como objetivo visualizar um determinado problema ou contexto e pensar em soluções a partir do que se vive no mundo virtual. Dentre as vantagens de utilizar um sistema gamificado pode-se destacar o envolvimento e a motivação dos participantes, os quais tendem a ser muito maior do que com os métodos tradicionais, também há uma maior facilidade de acessar os conhecimentos, pois no ambiente virtual aplica-se a teoria e a prática simultaneamente, além de proporcionar feedback em tempo real e a competição saudável entre os envolvidos. A gamificação, porém, não implica em criar um game, mas sim em usar as mesmas estratégias e métodos para resolver situações no mundo real, como se resolveria no mundo virtual. Acredita-se que por meio dela seja possível transformar o comportamento do aluno para desenvolver determinadas funções, utilizando-se de experiências lúdicas para motivar a realização de distintas atividades.

Muitos jogos estão sendo desenvolvidos com o objetivo de educar ou de treinar alguma habilidade, estes envolvem, principalmente, as áreas da Educação e da Computação. Isto posto, os games fazem parte das novas tecnologias que estão sendo usadas para a criação de AVAs, como citado anteriormente. Por outro lado, jogos digitais são tradicionalmente controlados por consoles estáticos por intermédio dos quais o usuário, colocado em frente a um monitor ou a uma televisão, interage com o jogo. Essa forma de relação tem sido apontada como uma das causas do aparecimento de problemas de ordem músculo-esquelético e de obesidade. Ballard e colaboradores (2009) relacionam o excesso de interação com os jogos ao sedentarismo e à obesidade, sugerindo a redução do tempo de uso dos mesmos e de computadores. É cada vez mais frequente o uso de smartphones pelos jovens entre 9 e 17 anos e, segundo pesquisa realizada pelo Centro Regional de Estudos para o Desenvolvimento da Sociedade da Informação (CETIC) em 2017, 84\% de crianças e adolescentes nesta faixa etária acessam a internet todo dia, sendo que $91 \%$ o fazem de celulares (CETIC, 2018).

Com toda esta tecnologia, o sujeito contemporâneo acaba por tornar-se mais sedentário, e com o passar do tempo mais suscetível à doenças relacionadas à inatividade física. Os adolescentes estão na maior parte do tempo com os seus celulares e para eles o aparelho geralmente desperta muito mais interesse do que a aula. Neste contexto, percebe-se a necessidade de disponibilizar ao professor uma ferramenta em que possa auxiliá-lo no processo de engajamento de alunos nas atividades de aprendizagem, em específico para as aulas de educação física, de forma simples e lúdica, a qual motive e incentive os jovens a praticarem atividades físicas. Diante destas considerações, surgem questões sobre as possibilidades e repercussões de um aplicativo (App) gamificado no processo de motivação e engajamento de alunos nas aulas de 
VIII Congresso Brasileiro de Informática na Educação (CBIE 2019)

Anais do XXV Workshop de Informática na Escola (WIE 2019)

educação física e a perspectiva do professor em ter uma ferramenta auxiliar na mediação das suas aulas.

\section{Método}

Este artigo é parte de três pesquisas envolvendo a produção de conhecimento com a possível associação entre tecnologias digitais e atividade física. A primeira, desenvolvida no âmbito de trabalho de conclusão de curso de Ciência da Computação, a segunda, dissertação de Mestrado em Educação, e a terceira, relativa a uma tese de Doutorado em Educação, a qual pretende relacionar a pesquisa a criação de wearable conectado ao aplicativo, a partir da produção de dados por sensores nas aulas de educação física e no cotidiano de estudantes da educação básica. As pesquisas estão em desenvolvimento no Grupo de Pesquisa em Cultura Digital na Educação (GEPID), em parceria com o Programa de Pós-Graduação em Educação, da Universidade de Passo Fundo.

Esse estudo foi elaborado a partir de uma base utilizando a plataforma Trello, na qual foram desenvolvidas as fases de criação, um brainstorm para elaboração do aplicativo. A escolha do nome Move Your Body (MYB) deve-se ao dispositivo ter relação às aulas de atividade física, ao movimento, como também pelo fato do aplicativo ter uma narrativa de jornada espacial, fazendo alusão sonora ao filme Mens In Black (MIB). Para o desenvolvimento do aplicativo foi usado como motor do App a UnityEngine, por dispor de vasta documentação, funcionalidades e pela possibilidade de compilação do aplicativo em várias plataformas. Para o armazenamento dos dados produzidos pelo App foi utilizado o Firebase Database do Google, por apresentar fácil integração com o Unity e alta segurança no arquivamento dos dados, além de dispor de integração com diferentes plataformas como IOS, Web e Android nativo.

O desenvolvimento do aplicativo foi iniciado no segundo semestre de 2018, testado no primeiro semestre de 2019, sendo que a aplicabilidade às pesquisas de mestrado e doutorado ocorrerá a partir do segundo semestre de 2019. A utilização do aplicativo dar-se-á por estudantes do $7^{\circ}$ ano do ensino fundamental, de escola particular, da cidade de Passo Fundo/RS, em que a escolha da instituição de ensino deve-se à proximidade conceitual com a base teórica de uma das pesquisas. É importante ressaltar que o aplicativo está em fase experimental (Beta) e que todas as pesquisas envolvidas se tratam de um estudo de caso, sendo asssim a sua utilização irá gerar dados, através das impressões dos professores e alunos, para o aprimoramento do mesmo.

\section{Resultados e discussões}

A utilização de dispositivos móveis é cada vez maior de acordo com pesquisa realizada pelo Centro Regional de Estudos para o Desenvolvimento da Sociedade da Informação (CETIC, 2018). O estudo aponta que 85\% da população brasileira, entre 9 e 17 anos, utilizam internet a partir do telefone celular. A crescente demanda de informação e as características de praticidade e agilidade que estes equipamentos possuem podem ser usadas em benefício de pessoas, visto que facilitam o transporte e a conexão por rede, além de possuir boa capacidade de processamento e fácil manuseio, o que oferece um significativo custo benefício ao usuário. Neste artigo, descreve-se o processo de 
VIII Congresso Brasileiro de Informática na Educação (CBIE 2019)

Anais do XXV Workshop de Informática na Escola (WIE 2019)

desenvolvimento da interface dos alunos do aplicativo gamificado Move Your Body visando reconhecer o potencial da gamificação como elemento mediador e engajador para as aulas de educação física entre escolares do ensino fundamental anos finais.

\subsection{Gamificação e seus elementos aplicados no MYB}

A gamificação é proveniente da popularidade dos jogos eletrônicos e de suas características que inspiram a ação, a solução de problemas, a aceleração do aprendizado em várias áreas do conhecimento (FARDO, 2013). Ela inclui o melhoramento de um serviço, tornando as atividades mais atrativas, divertidas e relevantes, levando o participante, por meio do lúdico, desenvolver estratégias, métodos e pensamentos que possa ser aplicado em situações reais. Para que o usuário se sinta motivado e envolvido com o aplicativo, elaborou-se uma combinação de elementos e da relação dos mesmos para produzir uma experiência adequada a partir do pensamento da criação de jogos. Segundo Alves (2015), os elementos dos games são padrões regulares que podem ser estabelecidos de diferentes maneiras. Esses elementos são separados em três categorias: dinâmica, mecânica e estética.

A dinâmica é o fator que atribui lógica e harmonia ao processo do game, e determina os princípios pelos quais o game se fundamenta. Os elementos que a compõem são: progressão, que consiste na possibilidade de acompanhar seu próprio progresso; constrições, são os obstáculos responsáveis por engajar o usuário; relacionamento, que busca estabelecer estratégias de relação social. A mecânica promove a ação, que faz com que o jogador fique motivado a continuar jogando. Os elementos que a compõem são: estado de vitória, jogador que ganha a partida ou atinge um objetivo; desafios, deve-se completá-los para que se atinja o estado de vitória; feedback, retorno do sistema para que o jogador perceba que é possível alcançar um objetivo; recompensas, são benefícios concedidos ao jogador; aquisição de recursos, moedas de troca obtidas ao completar ações; cooperação e competição, promovem no jogador o desejo de cooperar e competir com os demais. A estética, como o próprio nome diz, pode ser encarada como interface entre a dinâmica e a mecânica. Os elementos que a compõem são: realizações, mecanismos de recompensas ao jogador; avatares, representação visual de como é o personagem do jogador; badges, distintivos virtuais conquistados ao atingir um objetivo; boss fights, consiste em um ou mais desafios maiores que os habituais; desbloqueio de conteúdo, algo que só será desbloqueado após realizar determinada ação; níveis, são diferentes graus de dificuldade que vão aumentando no decorrer do jogo; score, diz respeito à contagem de pontos acumulados durante o game; gráfico social, sistema gamificado como parte de um círculo social; bens virtuais, benefícios que os jogadores estão dispostos a pagar. Dentre os componentes de gamificação existentes optou-se por utilizar no aplicativo os seguintes:

Tabela 1. Gamificação aplicativo MYB - Move Your Body 
VIII Congresso Brasileiro de Informática na Educação (CBIE 2019)

Anais do XXV Workshop de Informática na Escola (WIE 2019)

\begin{tabular}{|c|c|}
\hline Processos de Gamificação & Como isto se dá no aplicativo? \\
\hline \multicolumn{2}{|c|}{ Dinâmica: Atribui coerência e padrões à experiências. } \\
\hline $\begin{array}{l}\text { Progressão: Possibilidade de acompanhar o } \\
\text { progresso. }\end{array}$ & $\begin{array}{l}\text { O aluno visualiza no mapa a mobilidade das naves } \\
\text { conforme o professor lança as avaliações (Figura } 1 \text { ). }\end{array}$ \\
\hline $\begin{array}{l}\text { Constrições: Obstáculos para engajar o } \\
\text { usuário. }\end{array}$ & $\begin{array}{l}\text { Para passar das estações espaciais, os alunos do grupo só } \\
\text { conseguirão avançar se todos chegarem a mesma estação. }\end{array}$ \\
\hline $\begin{array}{l}\text { Relacionamento: Criação de estratégias de } \\
\text { relação social. }\end{array}$ & $\begin{array}{l}\text { O aluno tem a possibilidade de realizar doações de } \\
\text { suprimentos para os colegas atrasados, cada aluno receberá } \\
\text { ajuda uma vez. }\end{array}$ \\
\hline \multicolumn{2}{|c|}{ Mecânica: Elementos que promovem ação do jogador. } \\
\hline $\begin{array}{l}\text { Estado de vitória: Jogador que ganha a } \\
\text { partida ou atinge um objetivo. }\end{array}$ & $\begin{array}{l}\text { Este estado acontece quando os jogadores chegam ao novo } \\
\text { planeta ou passam de fase. }\end{array}$ \\
\hline $\begin{array}{l}\text { Desafios: O jogador deve completá-los para } \\
\text { que atinja o estado de vitória. }\end{array}$ & $\begin{array}{l}\text { O aluno precisa realizar as atividades propostas na aula de } \\
\text { educação física para receber bonificações no aplicativo. }\end{array}$ \\
\hline $\begin{array}{l}\text { Feedback: Retorno do sistema para que o } \\
\text { jogador perceba que é possível alcançar um } \\
\text { objetivo. }\end{array}$ & $\begin{array}{l}\text { Na realização positiva ou não das tarefas e no avanço ou } \\
\text { não no aplicativo o aluno recebe feedback dando } \\
\text { orientações e incentivando-o a seguir. }\end{array}$ \\
\hline $\begin{array}{l}\text { Recompensas: São benefícios concedidos ao } \\
\text { jogador. }\end{array}$ & $\begin{array}{l}\text { Os estudantes, ao cumprirem os desafios, irão receber } \\
\text { MYBs Coins (recompensas). }\end{array}$ \\
\hline $\begin{array}{l}\text { Aquisição de recursos: Possibilidade de } \\
\text { trocar moedas por recursos. }\end{array}$ & $\begin{array}{l}\text { Moedas são recebidas conforme a avaliação do professor } \\
\text { para o aluno e essas poderão ser trocadas por combustível. }\end{array}$ \\
\hline $\begin{array}{l}\text { Cooperação e competição: Promover no } \\
\text { jogador o desejo de cooperar e competir com } \\
\text { os demais. }\end{array}$ & $\begin{array}{l}\text { Formato do aplicativo é de um tabuleiro, o que traz a } \\
\text { sensação de competição e a cooperação, quando o aluno } \\
\text { necessitar interagir com a outra nave para que toda a } \\
\text { equipe evolua no game. }\end{array}$ \\
\hline \multicolumn{2}{|c|}{ Componentes (estética): interface entre a dinâmica e a mecânica. } \\
\hline $\begin{array}{l}\text { Realizações: Mecanismos de recompensas ao } \\
\text { jogador. }\end{array}$ & Possibilita o aluno ver que está avançando no game. \\
\hline $\begin{array}{l}\text { Avatares: Representação visual de como é o } \\
\text { personagem do jogador. }\end{array}$ & Os avatares são naves espaciais. \\
\hline $\begin{array}{l}\text { Níveis: São diferentes graus de dificuldade } \\
\text { que vão aumentando no decorrer do jogo. }\end{array}$ & $\begin{array}{l}\text { A medida que chega ao final do jogo aumenta o número de } \\
\text { pontos para avançar. }\end{array}$ \\
\hline
\end{tabular}


VIII Congresso Brasileiro de Informática na Educação (CBIE 2019)

Anais do XXV Workshop de Informática na Escola (WIE 2019)

\begin{tabular}{|l|l|}
\hline $\begin{array}{l}\text { Score: Diz respeito à contagem de pontos } \\
\text { acumulados durante o game. }\end{array}$ & $\begin{array}{l}\text { Representado pela quantidade de moedas que o jogador } \\
\text { possui. }\end{array}$ \\
\hline $\begin{array}{l}\text { Gráfico social: Sistema gamificado como } \\
\text { parte de um círculo social. }\end{array}$ & $\begin{array}{l}\text { Interação das naves no percurso. Elas avançam no } \\
\text { tabuleiro ao cumprirem as tarefas, ao contrário ficam } \\
\text { estacionadas nas estações espaciais até as demais } \\
\text { chegarem. }\end{array}$ \\
\hline
\end{tabular}

\subsection{Interfaces do aplicativo MYB}

O aplicativo possui três interfaces distintas, a primeira delas é chamada de Administrativa, na qual é possível cadastrar a escola, as turmas e os seus respectivos alunos, o professor e ter acessos aos dados do monitoramento da atividade física dos participantes da pesquisa. Essa interface será específica para uso da equipe de pesquisadores. A segunda é a interface do professor, em que o mesmo cadastra as aulas, informa antecipadamente sua intencionalidade e, após o seu desenvolvimento, faz a avaliação da participação dos alunos nas atividades, o que gera implicações na interface dos mesmos, ou seja, no processo de gamificação. A terceira interface, do aluno, é a que possui o processo de gamificação. Esta foi criada a partir de roteiro que narra a história da Terra que sofreu uma explosão, tornando-se inabitável e forçando a população a encontrar outro planeta onde possa recomeçar. Os estudantes serão representados por naves espaciais (avatares), as quais não serão identificadas no aplicativo com o intuito de não gerar competição direta entre os participantes.

Para tanto, os estudantes são divididos automaticamente em grupos de quatro integrantes, cada nave transportará um recurso importante para a sobrevivência da humanidade no novo planeta, incentivando o trabalho em equipe. Para avançar na interface gamificada, o aluno receberá pontuação na forma de combustível ou moedas chamadas de $M Y B$ Coins vindos do desempenho nas aulas de educação física, por meio da avaliação do professor. É importante lembrar que o objetivo da criação do aplicativo MYB não é a de criar uma plataforma de jogo, mas sim um aplicativo gamificado que sirva de ferramenta para engajar a participação nas aulas de educação física.

A interface individual completa do aluno pode ser visualizado nas Figuras 1 e 2. A Figura 1 apresenta a visão completa da tela, porém como o celular não comporta toda permitindo a visibilidade de toda a tela. Cada traço maior, amarelo, representa a aula, sendo definidas 17 aulas para o segundo semestre de 2019, o aluno poderá receber até 10 MYB Coins em cada aula. Para avançar uma posição, o aluno deverá conseguir no mínimo 7 pontos, ou seja, $70 \%$ da pontuação máxima para a aula e ter combustível suficiente na nave. Ao final, para conseguir chegar ao planeta deverá atingir no mínimo uma pontuação de 119 , sendo esta também $70 \%$ da pontuação máxima de todas as aulas.

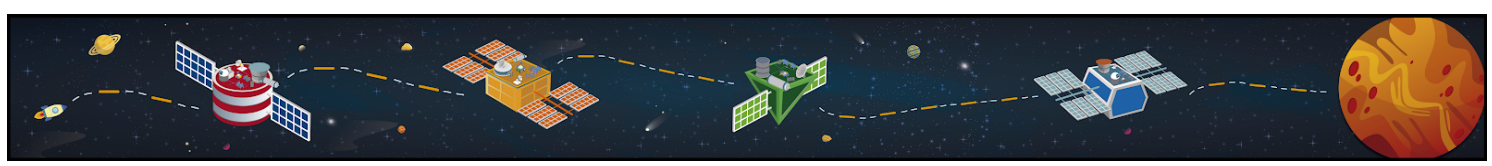

Figura 1. Visão completa da interface individual do aluno 
VIII Congresso Brasileiro de Informática na Educação (CBIE 2019)

Anais do XXV Workshop de Informática na Escola (WIE 2019)

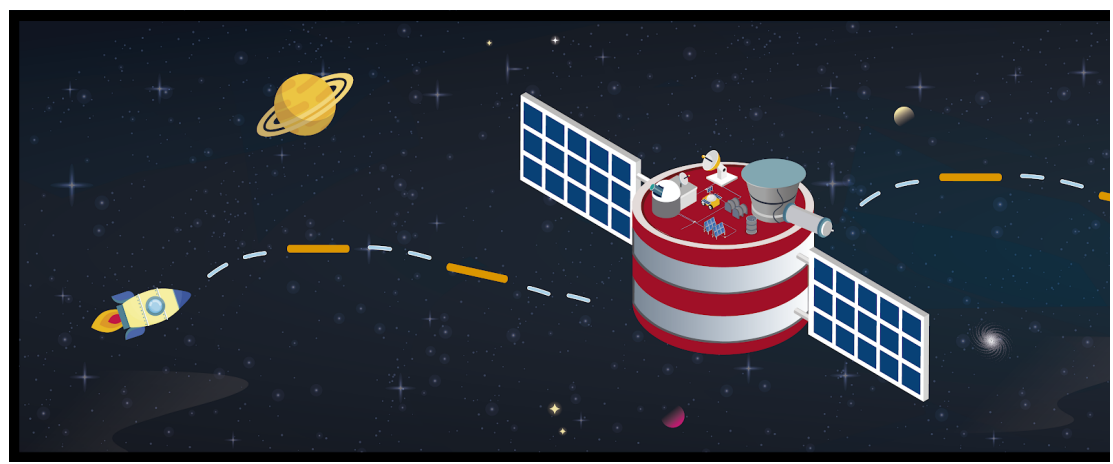

Figura 2. Visão ampliada da tela completa da interface individual do aluno

$\mathrm{Na}$ tela, exibida na Figura 1, pode-se visualizar quatro estações espaciais, nestas bases o aluno poderá reabastecer a sua nave utilizando os MYB Coins acumulados por realizar as atividades nas aulas de educação física, quanto melhor for o seu desempenho, mais moedas irá receber. Conforme o avanço no mapa, o combustível irá diminuindo e se tornará mais caro, exigindo um esforço maior por parte do aluno. Outra possibilidade de ação na chegada da base é a doação de moedas para as outras naves, cada usuário poderá transferir suas moedas até três vezes, entretanto cada uma das naves somente poderá receber uma doação durante todo o percurso. Este recurso foi pensado para gerar um comportamento de equipe entre os alunos, mesmo sem saber quem são os colegas representados pelas outras naves que compõem o grupo.

Enquanto a nave do aluno estiver parada em uma das estações espaciais é possível que este acesse ao menu e veja a visão geral de seu grupo (Figura 3), permitindo que o mesmo possa ver o progresso de sua equipe, ter uma noção de como está seu desempenho em relação à equipe e, a partir desta observação, elaborar estratégias para o avanço da mesma, como por exemplo: melhorar seu desempenho nas aulas, doar moedas para as outras naves ou estimular a turma nas aulas de educação física para que todos possam avançar, conseguindo boas pontuações para chegarem juntos no novo planeta.

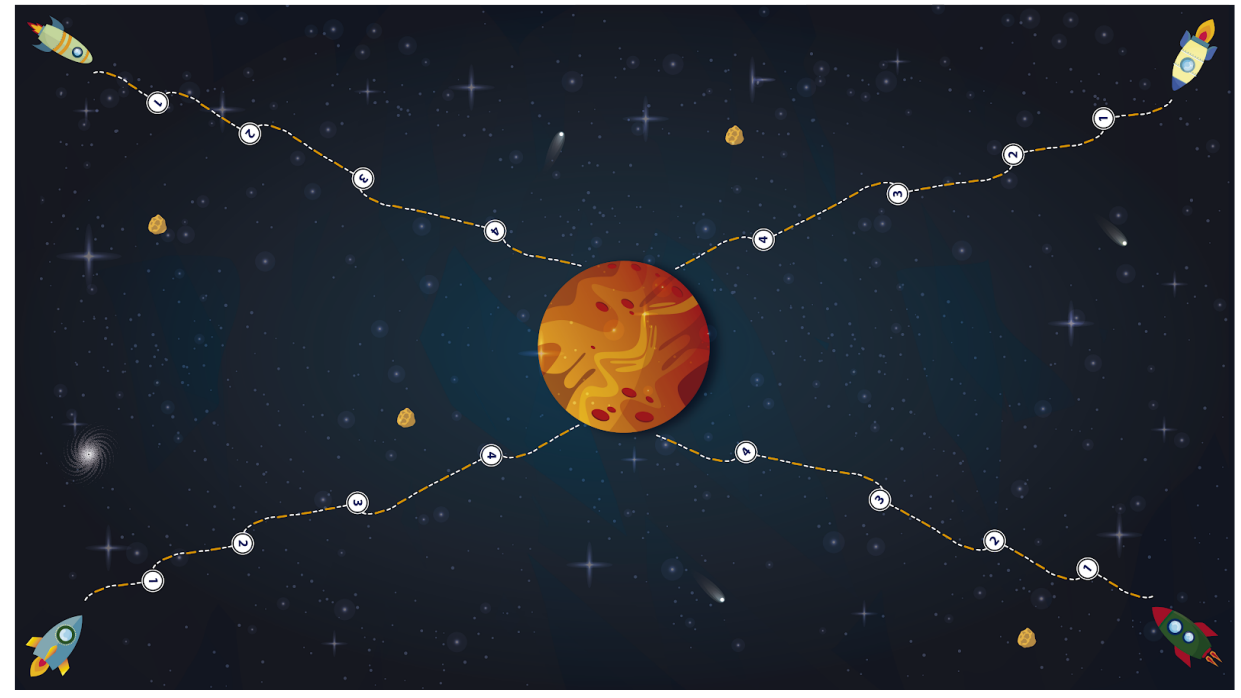

Figura 3. Visão do grupo do aluno 
Durante o percurso, ou seja, no decorrer das aulas que vão sendo desenvolvidas, o professor vai realizando as avaliações após as mesmas e os dados gerados são convertidos em pontos que vão movimentar as naves. Conforme os resultados vão sendo liberados, pelo professor, feedbacks de um droid chamado Move19, representado na Figura 4, irão aparecer para o aluno dando um retorno sobre seu desempenho, parabenizando o seu desempenho ou a melhora em caso insatisfatório.
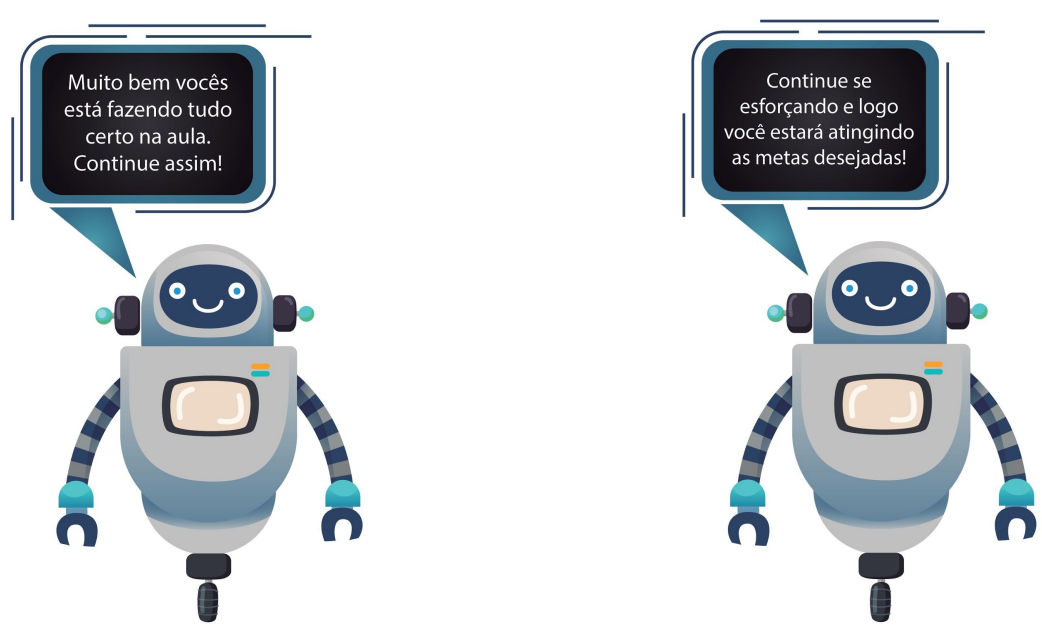

Figura 4. Droid Move19 e feedback para alunos.

\section{Conclusões iniciais}

$\mathrm{Na}$ contemporaneidade, verifica-se uma diminuição do interesse dos jovens em prol de seu smartphone e de outras plataformas quando o assunto é sobre momentos formais de aprendizagem, desenvolvidos por meio de aulas expositivas ou em atividades que envolvam a atividade física. Entretanto, acredita-se que seja possível fazer deste padrão de comportamento, frente ao uso das tecnologias digitais, um benefício e disponibilizar ao professor uma ferramenta que o auxilie no engajamento de seus alunos nas atividades propostas, tornando-as mais atrativas para os alunos e que sua realização se dê, não por obrigação, mas por estarem motivados pelo contexto criado a partir do uso de um aplicativo gamificado.

Acredita-se que as demais pesquisas associadas a esse estudo poderão adensar os dados dessa prática por serem desenvolvidas no contexto real e de forma longitudinal. Outra questão relevante é o desenvolvimento de pesquisa de forma interdisciplinar, como foi o caso desse estudo e das demais pesquisas citadas anteriormente. A participação de pesquisadores de diferentes campos do conhecimento em busca da solução de um problema real, propicia encontrar uma solução mais efetiva para o mesmo.

Por fim, sugere-se o desafio de criação de diferentes aplicativos gamificados para o contexto educacional, como forma de engajar e motivar os estudantes para a aprendizagem significativa nos diferentes componentes curriculares, ampliando o contexto específico deste estudo, a educação física. 
VIII Congresso Brasileiro de Informática na Educação (CBIE 2019)

Anais do XXV Workshop de Informática na Escola (WIE 2019)

\section{Referências}

ALVES, F. (2015) "Gamification: como criar experiências de aprendizagem engajadoras um guia completo: do conceito à prática." 2 ed. Ver e ampl. São Paulo: DVS Editora.

ALMEIDA, M. E. B. (2008). "Educação e tecnologias no Brasil e Portugal em três momentos de sua história.” Educação, Formação e Tecnologias, 1, 1-14.

BORGES, S. S.; REIS, H. M.; DURELLI, V. H. S.; BITTENCOURT, Ig I.; JAQUES, P. A.; ISOTANI, S.(2013) "Gamificação Aplicada à Educação: Um Mapeamento Sistemático.” In: Anais do XXIV Simpósio Brasileiro de Informática na Educação (SBIE 2013), p. 234- 243. DOI: 10.5753/CBIE.SBIE.2013.234.

CETIC.BR. (2017) "Pesquisa sobre o uso das Tecnologias de Informação e Comunicação nas escolas brasileiras - TIC Educação 2017." Disponivel em: https://www.cetic.br/media/docs/publicacoes/2/tic_edu_2017_livro_eletronico.pdf . Acesso em: 29 de maio de 2019.

DE LISI, R., WOLFORD, J. L. (2002). “Improving chidren's mental rotation accuracy with computer game playing.” J. Genetic Psychol., 136, 272-282.

FALKEMBACH, G. A. M. (2006). "Desenvolvimento de Jogos Educativos Digitais utilizando a Ferramenta de Autoria Multimídia: um estudo de caso com o ToolBook Instructor." Novas Tecnol. Educ., 4, 1-10.

FARDO, M. L. (2013) “A gamificação aplicada em ambientes de aprendizagem.” 2013. Dissertação (Pós-Graduação em Educação) - Universidade de Caxias do Sul, Caxias do Sul.

KAPP, K. M. (2012) “The Gamification of learning and instruction: Game-based methods and strategies for training and education." Pfeiffer. Hoboken, NJ.

VIANNA, Y., VIANNA, M., MEDINA, B. e TANAKA, S. (2013) “Gamification, Inc: Como reinventar empresas a partir de jogos.” MJV Press, Rio de Janeiro. 